\title{
BLOOD ELECTROLYTE STUDIES DURING HISTAMINE SHOCK IN DOGS
}

\author{
By DANA W. ATCHLEY, DICKINSON W. RICHARDS, JR., \\ AND ETHEL M. BENEDICT \\ (F rom the Department of Medicine, College of Physicians and Surgeons, Columbia University, \\ and the Presbyterian Hospital, New York)
}

(Received for publication November 5, 1930)

These experiments were undertaken in order to study the changes occurring in the acid-base equilibrium during acute shock. The injection of histamine into an animal causes capillary dilatation, with drop in blood pressure and stasis not unlike the picture of shock as it occurs complicating the course of various clinical conditions. A response so easily produced and readily controlled seemed eminently suitable for a physicochemical study of shock.

Dale and Laidlaw (1) showed that, during the course of histamine shock there was a concentration of the circulating blood, in the sense that the ratio of corpuscle volume to serum volume was markedly increased. Inasmuch as the primary effect of histamine had been found to be capillary dilatation, they inferred that this concentration was due chiefly to transudation of serum through the capillary walls. The scope of their investigations did not include any observations on the physicochemical changes in the blood. In a later study, they also found that there was a corresponding decrease in plasma volume, and that the protein content of the serum during histamine shock remained essentially unchanged; and their conclusion was that whole serum escaped through the capillary walls. Lewis (2) offered indirect evidence in favor of the same conclusion by finding that the proteins of a histamine wheal (skin) closely approximated those of blood serum.

The observations here presented were made immediately before and during histamine shock in dogs and include serum electrolyte partitions, hematocrit determinations and in certain instances $\mathrm{O}_{2}$ capacity and serum $\mathrm{pH}$. 


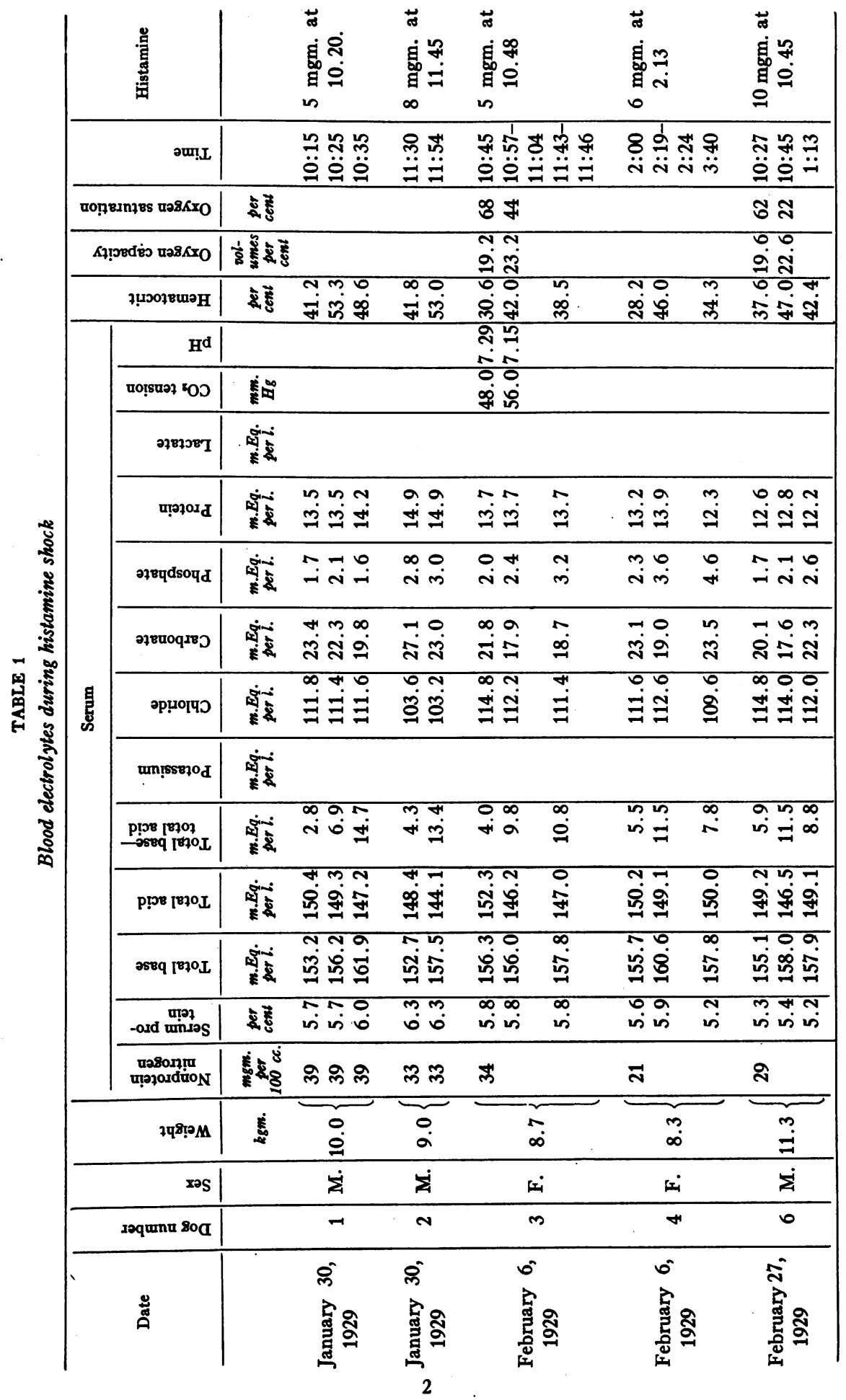




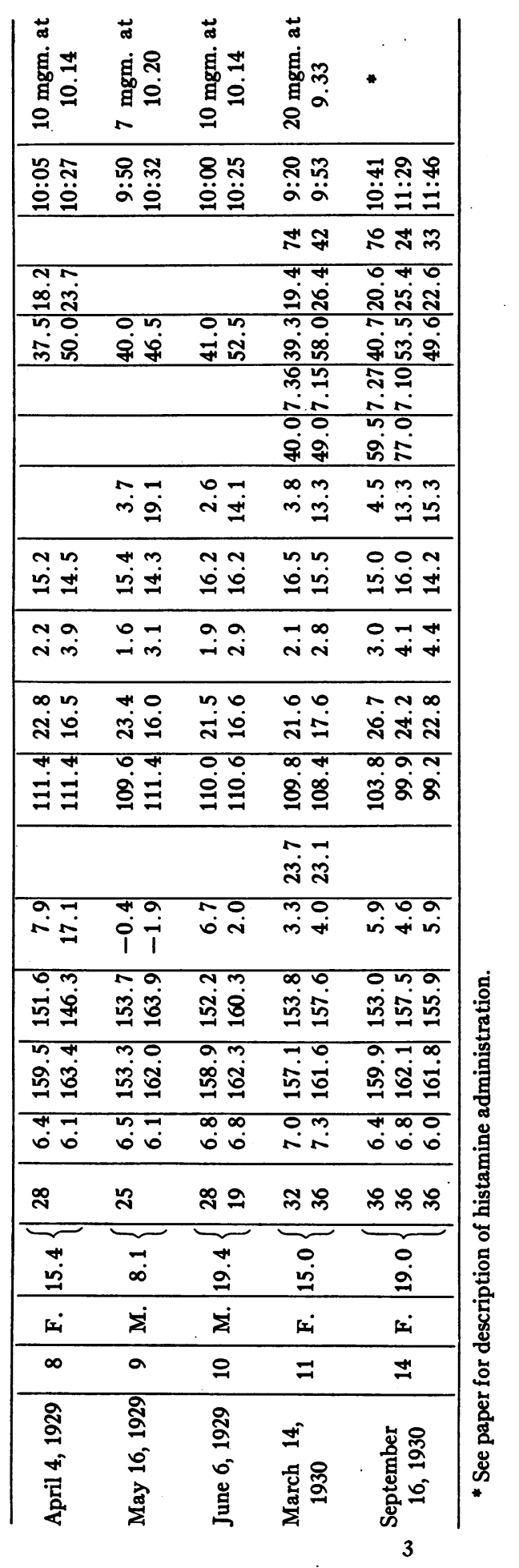




\section{METHODS}

Dogs were used in all experiments. The animal was strapped on the operating board, and $80 \mathrm{cc}$. of blood drawn under oil from the external jugular vein; the dogs nearly always submitted to this procedure quietly. A solution of histamine acid phosphate containing 5 to $12 \mathrm{mgm}$. of histamine base was then injected rapidly into a leg vein. The usual reaction to this was a certain amount of convulsive struggling lasting about half a minute, associated with defecation, salivation and urination. The pulse became thready or imperceptible, a deep red flush gradually appeared over the skin, turning in the course of a minute or two to a deep cyanosis. At the height of this latter effect, another $80 \mathrm{cc}$. sample of blood was drawn from the jugular vein. In certain of the animals a third sample was drawn at a later period (see table 1).

In the last experiment ( $\operatorname{dog} 14)$, the animal was anesthetized, and a considerable variation in technique employed. The special purpose of this experiment was to discover whether the transient convulsive response to histamine, in the conscious animal, had been an important factor in the changes we had found. This dog was first anesthetized rapidly with open ether, then injected with 5 grams of sodium veronal intravenously. Deep anesthesia was produced, inspirations were greatly decreased for the next half hour, but subsequently increased again. The dog was left undisturbed for the first 2 hours after veronal injection. At the end of this time, the animal was completely relaxed, breathing slowly and evenly, and the heart action was apparently normal. The carotid artery was exposed, cannulized, and connected with a mercury manometer for the registration of blood pressure. (Glucose solution was used in the connecting tubing, to prevent electrolytes entering the circulation.) Jugular and femoral veins were exposed to facilitate taking of blood samples and injection of histamine. After a preliminary blood sample had been drawn, histamine injections were begun, and given almost continuously, at the rate of 0.1 to $0.5 \mathrm{mgm}$. every 1 to 2 minutes, for the next hour. During the last 40 minutes of this time, the arterial blood pressure remained between 35 and $40 \mathrm{~mm}$. Blood was drawn 40 minutes after the start of the histamine injections, and again 20 minutes later. No convulsive movements of any kind were noted during the course of these injections.

The chemical methods have, with the few exceptions noted below, been discussed in a previous paper (3). Lactic acid was determined by the method of Friedemann, and Kendall (4). Blood gas analyses were performed with the Van Slyke-Neill (5) and Haldane apparatus, the technique of blood manipulation being essentially that of Austin, Van Slyke et al (6). For the determination of serum $\mathrm{pH}, \mathrm{CO}_{2}$ dissociation curves of whole blood were constructed; the calculations were made with the aid of the Van Slyke-Sendroy (7) charts. In calculating base bound to protein, Van Slyke's formula for human serum was used, as none is available for dogs' blood. Hematocrits were done on samples containing equal and constant amounts of oxalate. 


\section{RESULTS AND DISCUSSION}

The results of the experiments are presented in table 1 . It is obvious from the changes in hematocrit and (when measured) $\mathrm{O}_{2}$ capacity that a striking concentration of the blood occurs during histamine shock. The greatest increase was 18.7 per cent (by hematocrit reading) in Dog 11, and in no instance was it absent. Furthermore, it appears clear that this was not a concentration by loss of water, for the protein percentage of the serum changed very little, if any, in most of the animals. In such a brief experiment the serum protein concentration is a fairly reliable index of dilution by water alone. The concentration of the blood during histamine shock seems, therefore, to be dependent upon the transudation of whole serum through the capillary walls; as shown previously by Dale and Laidlaw.

As the work progressed it was observed that there was always an increase in the undetermined acid of the serum, i.e., total base minus total acid (B-A), during the period of shock. As shock causes striking vascular stasis in the tissues with probably significant interference with their oxidative processes, it was suspected that this undetermined acid was lactic acid. Lactate determinations on the last four animals proved this assumption to be correct. As much as $15 \mathrm{~m}$. eq. of lactate were found in one of the dogs. The sudden, brief twitching that occurred with the injection of histamine in the conscious animal seemed insufficient to cause the lactic acid acidosis, and the experiment on Dog 14, performed under veronal anesthesia, indicates that excessive lactic acid production occurs in the absence of any convulsive muscular movements. The occurrence of lactic acid acidosis is, therefore, a constant accompaniment of histamine shock and is probably due to tissue anoxemia.

Another constant change during histamine shock was a considerable percentage increase in serum phosphate. No satisfactory explanation of this finding is apparent from these experiments.

An interesting and somewhat unexpected observation was the effect of histamine shock on the total base of the serum. In every instance there was an increase in total base, and in 6 out of 10 dogs it was well outside the limits of error of the method. When the lactic acid increase was large, there was always a significant increase in base. In a 
fairly large series of total base determinations on animals and human beings under a variety of conditions, we have never seen increases in serum total base independent of base administration. It is the more noteworthy, therefore, that the only instance of consistent base increase to be found in the literature was reported by Henderson and Bock (8) following the lactic acid acidosis of muscular fatigue. The acidosis of histamine shock and muscular exercise are similar not only in the fact that lactic acid is the common cause, but also by virtue of the fact that they both occur rapidly. It is impossible to determine from our data the relative importance of these two factors in the production of the unusual compensatory mechanism evidenced by an increase in serum cations. In $\operatorname{dog} 11$, potassium determinations were made in order to throw light on the source of the increased base. No change in potassium was found which leads one to infer that the base increase was probably not drawn from the cells.

Serum bicarbonate decreased consistently as base was needed for lactate, for the increase in total base was less than the lactate production. It should be noted that a slower induction of shock (and thus acidosis) in the anesthetized animal was accompanied by a decrease in chloride greater than that of bicarbonate. In the other animals chloride concentrations were all surprisingly constant. There was a considerable decrease in serum $\mathrm{pH}$ and increase in $\mathrm{CO}_{2}$ tension in the three cases measured. As would be expected, $\mathrm{O}_{2}$ saturation decreased markedly in the four animals in which that determination was included.

\section{CONCLUSIONS}

Acute histamine shock in dogs is accompanied by:

1. Concentration of the blood due to the transudation of whole serum. This is proved by the striking change in hematocrit and $\mathrm{O}_{2}$ capacity with no significant accompanying change in serum protein.

2. Uncompensated lactic acid acidosis, with the required base afforded by: (a) increase in serum total base; (b) decrease in serum bicarbonate. One experiment performed under veronal anesthesia was sufficiently similar to the other experiments to suggest that this formation of lactic acid was not due to muscular contraction.

3. Increase in inorganic serum phosphate unexplained by these experiments.

4. Decrease in $\mathrm{O}_{2}$ saturation. 


\section{BIBLIOGRAPHY}

1. Dale, H. H., and Laidlaw, P. P., J. Physiol., 1910, xli, 318. The Physiological Action of $\beta$-Iminazolylethylamine; ibid., 1919, lii, 351. Histamine Shock.

2. Lewis, T. The Blood Vessels of the Human Skin and Their Responses. London, 1927.

3. Atchley, D. W., and Benedict, E. M., J. Clin. Invest., 1930, ix, 265. Serum Electrolyte Studies in Normal and Pathological Conditions: Pneumonia, Renal Edema, Cardiac Edema, Uremic and Diabetic Acidosis.

4. Friedemann, T. E., and Kendall, A. I., J. Biol. Chem., 1929, lxxxii, 23. The Determination of Lactic Acid.

5. Van Slyke, D. D., and Neill; J. M., J. Biol. Chem., 1924, lxi, 523. The Determination of Gases in Blood and Other Solutions by Vacuum Extraction and Manometric Measurement. I.

6. Austin, J. H., Cullen, G. E., Hastings, A. B., McLean, F. C., Peters, J. P., and Van Slyke, D. D., J. Biol. Chem., 1922, liv, 121. Studies of Gas and Electrolyte Equilibria in Blood. I. Technique for Collection and Analysis of Blood and for Its Saturation with Gas Mixtures of Known Composition.

7. Van Slyke, D. D., and Sendroy, J., Jr., J. Biol. Chem., 1928, lxxix, 781. Studies of Gas and Electrolyte Equilibria in Blood. XV. Line Charts for Graphic Calculations by the Henderson-Hasselbalch Equation.

8. Henderson, L. J., Blood. A Study in General Physiology. Yale University Press, 1928, p. 244. 